\title{
The Fairness Relationship with Trust and Trustworthiness in Mobile Sector in Saudi Arabia
}

\author{
Mohammed S. Al-Amri ${ }^{1} \&$ Abdulaziz J. Al Shammary ${ }^{2}$ \\ ${ }^{1}$ Department of Management, College of Business Administration, King Saud University, Riyadh, Saudi Arabia \\ ${ }^{2}$ College of Business Administration, Yamamah University, Riyadh, Saudi Arabia \\ Correspondence: Mohammed S. Al-Amri, Department of Management, College of Business Administration, \\ King Saud University, Riyadh, Saudi Arabia. E-mail: msruh28@ksu.edu.sa
}

Received: January 2, 2017

Accepted: February 22, 2017

Online Published: March 26, 2017

doi:10.5539/ijbm.v12n4p95

URL: https://doi.org/10.5539/ijbm.v12n4p95

\begin{abstract}
This study attempt to explore the relationship of most fairness factors (distributive, procedural, and interactional) which in turn contribute significantly to customer trust and trustworthiness, whereby we consider the study investigation and finding as an important key success of existing companies as well as market entrants, as the challenges and fast growing characterizing the market with a wide increasing range of demands versus narrow offers, whereby this mismatch affecting the perceived fairness and trust relationship and further influence temper of trustworthiness of both parties. The conceptual model, literature review and proposed hypotheses and its justification were been built based on the most related theories alike social exchange, equity and fairness heuristic theories and mutual previous studies in the same or in related field, the study was performed in Riyadh, Saudi Arabia, among (300) customers of different mobile providers, the results reported a positive relationship of proposed hypotheses which in turn proves the importance of fairness different dimension and the impact of the same on customer trust and trustworthiness.
\end{abstract}

Keywords: distributive fairness, procedural fairness, interactional fairness, trust, trustworthiness, customer, mobile sector, Saudi Arabia

\section{Introduction}

Fairness can be a source of competitive advantage (Loch et al., 2012) whereby the need and the importance of fairness become major and core business component issue as fairness spans the entire life cycle of a product start from design through to advice and after-sales service - and covers things like culture in the business that the client is dealing with (Glacier, 2013) further, some global cooperation have adapted fairness as part of their practice and set policies, a like Mitsubishi Cooperation "The company will act responsibly and will respect the highest social standard" (Mitsubishi Cooperation, 2006), synchronously, companies strive to attract talent who usually seek to be hired by best companies in an exchange fairness relationship "this year's best employers have focused on fairness" (Robert, 2016) thus we believe that the road map to a loyal customer and to be rated as trustworthy firm is through adapting fairness as part of the company culture and that start from inside the organization by building a proper procedural fairness that eliminates the errors or mistakes and present the company welfare entity and it is passion to it is customer satisfaction, and further to have well established interactional justice for each decision taken which would reflect the company dignity and respect to its customer, last but not least, to have distributive justice fundamentals to ensure fair and acceptable outcomes.

\subsection{The Problem of the Study}

The emerging challenges of 21 century become a new trend for business organizations, whereby cost reduction, staff satisfaction, and productivity are not the only concern of today leaders, but the arise challenge chain list consists of organization justice and its relationship with trust which an important concern that had been highlighted by different researchers. Further Saudi Mobile Companies are considered as a part of today business organizations, thus they are seeking a unique benchmark in the market, but on another hand they meet with different challenges toward better customer competitive services, consequently we believe they have to step behind the common management tools and adapt to latest and modern practices that would help to achieve efficient and effective services, for closer look, the Saudi Mobile Sector have more than 53 million mobile 
subscriber in 2015 (Aljazira Capital, 2016) and the sector stepping into a new reality that has mass challenges, alike dramatically lowering of oil prices, fingerprint registration of SIM cards, limited growth in revenue, a cut in government spending, restriction of online free calls, and foreigner investors entrants, hence the needs to retain and attract customers present a key tactics and objective for all mobile companies as the primary financial turnover are generated from the single end user (the consumer), thus our study emphasis on the subject of fairness are today headline for the sector, as perceived fairness relationship customer trust and further set the marks of trustworthiness relationship, where in turn that relationship affect the company overall success and would require from company leaders to adapt into the modern and up to date challenges and practices. Accordingly our study correlated to that foundation as we seek to understand, examine and find the relationship of fairness relationship with trust and trustworthiness.

\subsection{The Importance of the Study}

The mobile sector in Saudi Arabia took place when the founder of Saudi Arabia King Abdulaziz missionized the need to strength the communication between different regions, King Abdulaziz order to establish the department of telegram, mail and telephone in the year 1926 which covers the vital communication needs of people as well as the government, in 2003 the department has been transformed to ministry of telecommunication and information technology with a wider responsibility to meet the increasing demand of the service, however first Saudi Company of Telecommunication, branded as STC has been established in 1998 named Saudi Telecommunication Company, which monopolize the mobile sector for almost 7 years till 2005 whereby Etihad Telecommunication Company branded as Mobily joined the market, and further a third company branded by Zain joined the market in the year 2007, another two forward integration company has joined the market in 2015 as fixed services extender named Virgin Mobile Saudi consortium branded as Virgin Mobile who are working exclusively for Mobily Company and the second company Etihad Jawraa for Telecommunication and Information Technology Company branded as Lebara Mobile who work exclusively for STC. (Ministry of Communication and Information Technology, 2016).

The increase demand to meet the market up to date practices from people as well as from other service beneficiary was a never ended challenge for those provider, just recently a new demand of having fair pricing strategy has become a trend in the society requesting for fair distributive fairness as people don't compare themselves locally but even across Mideast and Asia with regards to the speed of the internet, the limited data capacity and even the quality of the service, as a result many boycott campaigns took place in social exchange applications a like Twitter, Face book and What's App, whereby we refer such relationship to our study subject of fairness relationship with trust and trustworthiness.

Therefore, the importance of our study take place by build touch base, reflect and bring closer the customer feeding as they present the end user and beneficiary of the exchange relationship, further the importance of this study are correlated with its objectives as we aim to validate the relationship between fairness, trust, and trustworthiness, and further, present and highlights the importance and relationship of the finding, and finally to build a base between literature studies and market practices that would help students, scholars and the companies in the field of mobile sector.

\subsection{The Objectives of the Study}

- Provide an appropriate theoretical framework that illustrates organizational fairness.

- To assess the fairness relationship with trust and trustworthiness.

- It will fill a gap in the research literature on the organizational fairness.

- It is also expected that the result of this study will inform the decision makers in Saudi Mobile Sector about the extent of organizational fairness among customers.

\section{Literature Review and Previous Studies}

This study aims to study the relationship between services fairness, the levels of customers' trust and trustworthiness. Thus, we have built our study model (figure 1), supported by most relevant and well known related three theories in the subject study filed, first is equity theory (Adams, 1965) which emphasizing how individuals manage their relationship with other (Huseman et al., 1987) and has been rated as the second highest scientific validity out of 72 organization behaviour theories (Miner, 2003), secondly is fairness heuristic theory (Lind and Thompson 2001) as it aim to explain how people react to outcomes of their dealings with surrounding, and makes some predictions concerning the relationship between perceived fairness of procedures, perceived fairness of outcomes and acceptance of outcomes (Árnadóttir, 2002), last is social exchange theory (Blau, 1964) as it focus on people relationship outcomes are based on their joint actions (Sutton and Douglas 2013) 
accordingly, our study result are elaborated and discuss based on the study model and suggested hypotheses.

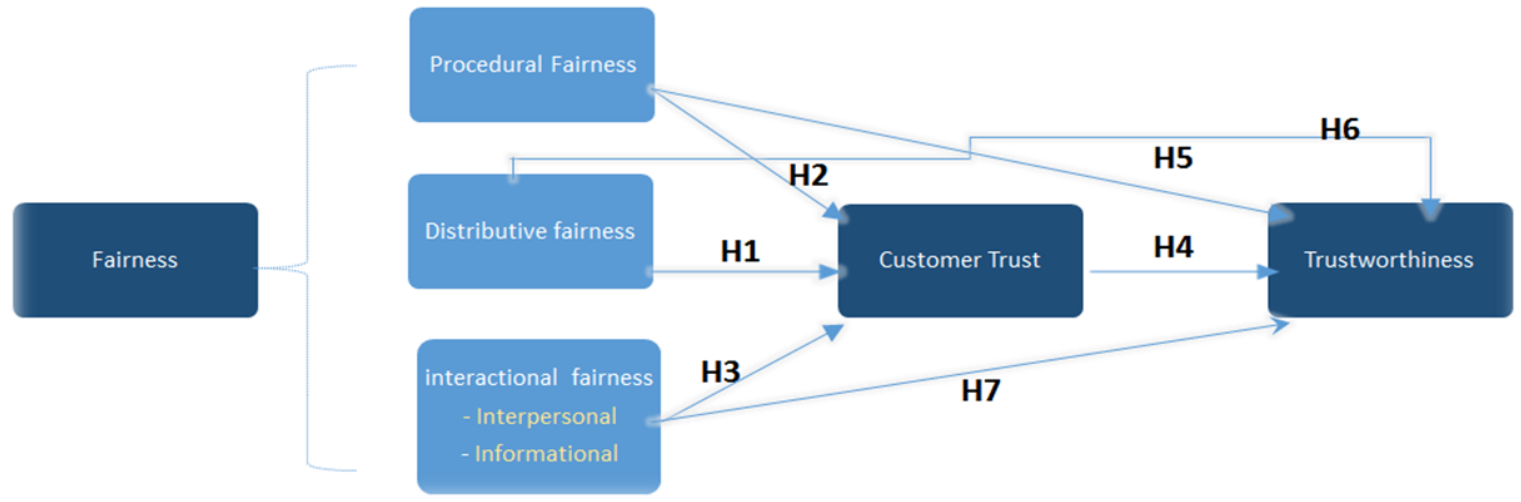

Figure 1. The study model

\subsection{Fairness Dimensions}

Equity, fairness, and justice have been used interchangeably in different theory a like equity theory (Adams, 1965) and fairness heuristic theory (Lind and Thompson 2001), further scholars has define fairness term as the concept of justice and interpreted as being equal in provision, in opportunity, or in result (Jenkins, 2000). The term fairness was the most comfortable to be used compare to other two terms equity and good relationship based on a social research conducted in Scotland aims to build on existing evidence on public attitudes to explore further the Scottish public's understanding of the concepts 'equality', 'fairness' and 'good relations' (Dobbie et al., 2010). Therefore, we use the term fairness to refer to the same concept or meaning of justice, equity or good relationship.

Numerous researchers built extended and/or correlated ranges of fairness, some approaches suggest that fairness is consist of three factors of procedural, distributive, and interactional fairness, whereby interactional fairness compromise interpersonal and informational fairness (Wan, 2015) other researchers alike (Colquitt, 2001) in his study of dimensionality of organizational justice has identify four types of fairness "procedural, distributive, interpersonal, and informational, as further highlighted in Figure 2.

\begin{tabular}{|c|c|}
\hline Measure item & Source on which item is based ${ }^{a}$ \\
\hline \multicolumn{2}{|l|}{ Procedural justice } \\
\hline \multicolumn{2}{|l|}{ The following items refer to the procedures used to arrive at your (outcome). To what extent: } \\
\hline 1. Have you been able to express your views and feelings during those procedures? & Thibaut \& Walker (1975) \\
\hline 2. Have you had influence over the (outcome) arrived at by those procedures? & Thibaut \& Walker (1975) \\
\hline 3. Have those procedures been applied consistently? & Leventhal (1980) \\
\hline 4. Have those procedures been free of bias? & Leventhal (1980) \\
\hline 5. Have those procedures been based on accurate information? & Leventhal (1980) \\
\hline 6. Have you been able to appeal the (outcome) arrived at by those procedures? & Leventhal (1980) \\
\hline 7. Have those procedures upheld ethical and moral standards? & Leventhal (1980) \\
\hline \multirow{2}{*}{\multicolumn{2}{|c|}{ Distributive justice }} \\
\hline The following items refer to your (outcome). To what extent: & \\
\hline 1. Does your (outcome) reflect the effort you have put into your work? & Leventhal (1976) \\
\hline 2. Is your (outcome) appropriate for the work you have completed? & Leventhal (1976) \\
\hline 3. Does your (outcome) reflect what you have contributed to the organization? & Leventhal (1976) \\
\hline 4. Is your (outcome) justified, given your performance? & Leventhal (1976) \\
\hline \multicolumn{2}{|l|}{ Interpersonal justice } \\
\hline \multicolumn{2}{|l|}{ The following items refer to (the authority figure who enacted the procedure). To what extent: } \\
\hline 1. Has (he/she) treated you in a polite manner? & Bies \& Moag (1986) \\
\hline 2. Has (he/she) treated you with dignity? & Bies \& Moag (1986) \\
\hline 3. Has (he/she) treated you with respect? & Bies \& Moag (1986) \\
\hline 4. Has (he/she) refrained from improper remarks or comments? & Bies \& Moag (1986) \\
\hline \multicolumn{2}{|l|}{ Informational justice } \\
\hline The following items refer to (the authority figure who enacted the procedure). To what exten & \\
\hline 1. Has (he/she) been candid in (his/her) communications with you? & Bies \& Moag (1986) \\
\hline 2. Has (he/she) explained the procedures thoroughly? & Bies \& Moag (1986) \\
\hline 3. Were (his/her) explanations regarding the procedures reasonable? & Shapiro et al. (1994) \\
\hline 4. Has (he/she) communicated details in a timely manner? & Shapiro et al. (1994) \\
\hline 5. Has (he/she) seemed to tailor (his/her) communications to individuals' specific needs? & Shapiro et al. (1994) \\
\hline
\end{tabular}

Figure 2. Conceptual model 
The researchers decided to proceed this study based on the three dimension of fairness (distributive, procedural, and interactional) due to the literatures and studies anxiety and differences aspect of fairness and the debates that surround it.

\subsection{Distributive Fairness}

Distributive justice refers to the perceived fairness of one's outcomes when a reward is allocated or a decision is made, people often make a judgment whether or not the outcome was fair (Mayer, 2009) in social science, distributive fairness is defined as perceived fairness of how rewards and costs are shared by or distributed across group members (Forsyth, 2006), an example of distributive fairness, every incoming freshman to a local college with a grade point above 3.0 might be offered a $\$ 500$ scholarship, this is a nice reward for students and parents who can afford the remaining tuition, but it is present no help to families that cannot afford the additional $\$ 6000 /$ year fees to attend the school (Michelle, 2013). There's a common argument that libertarians make against the idea of social or distributive justice (Matt, 2011) the term 'distributive justice' is not a neutral one, there is no more a distributing or distribution of shares than there is a distribution of mates in a society in which persons choose whom they shall marry (Robert, 1974), further point of view shared by (Hayek, 1978) "I must turn now against an abuse of the word [justice] which threatens to destroy the conception of law which made it the safeguard of individual freedom". A meta-analysis of the role of justice in the organization conducted by (Cohen-Charash and Spector 2001) found distributive justice is predicted to be related mainly to cognitive, affective and behavioural reactions to particular outcomes, accordingly, we define distributive fairness as the customer cognitive fairness which built based on his/her own experience encountered during certain exchanges relationship of good and/or services.

\subsection{Procedural Fairness}

Researchers defined procedural fairness as the methods the firm uses to deal with the problems arising during service delivery in aspects such as accessibility, timing/speed, process control, delay and flexibility to adapt to the consumer's recovery needs (Río-Lanza et al., 2009) furthermore, in service companies, procedural fairness has been define as the customer's perception of justice for the several stages of procedures and processes needed to recover the failed service (Mattila, 2001), an example of procedural fairness if a member of the public receives a speeding ticket (negative outcome) but was treated fairly during the interaction with the officer issuing the ticket (positive process), the driver is more likely to feel that the encounter was fair and is less likely to contest the ticket or register a complaint against the officer, the driver is also more likely to comply with the officer's requests, such as producing identification when asked, and to come away from the encounter with a positive opinion of the law enforcement agency (Kunard and Moe 2015).

One criticism of procedural justice model, (Hough et al., 2010) highlight that "it has been most often applied in English speaking countries with common-law legal systems will it 'work' in other contexts, such as continental Europe, where legal systems and the position of the police within them, are often very different? Such questions are of particular relevance given the ever-increasing pluralism and mobility of the modern world. Will the methods implied by 'process-based' policing, and the ends they aim for, 'work' across, and within, diverse multi-cultural situations?" in a meta-analysis study of the mediating role of intrinsic motivation conducted by (Zapata-Phelan et al., 2009) they found procedural fairness predicted both self-reported and free-choice based measures of intrinsic motivation, accordingly, we define procedural fairness as the degree of person acceptance of certain process and procedures in exchange relationship of goods or service.

\subsection{Interactional Fairness}

Interactional fairness has been defined as degree to which the people affected by decision are treated by dignity and respect (Schermerhorn et al., 2003), further it has been define as the attitudes and behaviours of the exchangers (Collie et al., 2002). Interactional justice can be further divided into interpersonal and informational components. Interpersonal justice reflects the degree of respect and propriety authority figures use when implementing procedures, and informational justice reflects the degree of justification and truthfulness offered during procedures (Jason and Jessica 2011) For example of interpersonal fairness is treating all employees with respect and dignity showcases equity in the organization (Prathamesh, 2012). Subsequently, we define interactional fairness as the maturity of the relationship exchange between two parties.

\subsection{Fairness and Trustworthiness}

According to fairness heuristic theory, in an effort to cope with this dilemma, individuals use a "fairness heuristic" as a shortcut to determine whether or not to cooperate (Jason and Jessica 2011) furthermore anxiety or uncertain management theory suggest that intercultural encounter are characterized by high level of uncertainty 
and anxiety specially when culture variability is high, thus whenever two people meet for the first time there is uncertainty accompanied by feeling of uneasiness or anxiety, the theory suggest these feeling of anxiety are heightened in intercultural interaction (Judith, 2013). Thus we argue that fairness heuristic theory can explain how perceived fairness influences perceived trustworthiness.

In the subject of buyer and seller relationship in mobile sector, and the relationship between two party of customer and the seller, we assume the first part is unsure about the outcomes of the service provider and the relationship can be predicated as uncomfortable due to anxiety barriers, as a result, customers are likely to form perceptions of trustworthiness about the service provider based upon fairness perceptions (procedural, distributive, and interactional). Hence based on the theoretical and findings, we propose the following hypotheses:

\section{1- Distributive fairness has a positive relationship with trustworthiness.}

\section{2- Procedural fairness has a positive relationship with trustworthiness.}

\section{3- Interactional fairness has a positive relationship with trustworthiness.}

\subsection{Trust and Trustworthiness}

Several terms has been used synonymously with trust a like cooperation, confidence and predictability (Mayer et al., 1995). Trust defined as the willingness of party to be vulnerable to the action of another party (individual or organization) based on positive expectation regarding the other party's motivation and/or behaviour (Harris et al., 2014) supportively, a meat-analysis study conducted in Vietnam found that trust is partly driven by the expectation of return from the trustee (Nguyen et al., 2012). Organizational trustworthiness model (figure 3) developed by (Mayer et al., 1995) has suggest three factors of trustworthiness (ability, benevolence, and integrity) would lead to trust. Ability refer to the group of skills, competencies, and characteristics that enable a party to have influence within some specific domain. Benevolence is the extent to which a trustee is believed to want to do good to the trustor, aside from an egocentric profit motive. Integrity refer to the adherence to a set of values that the other fined it acceptable, however organizational trustworthiness model also distinction between trust and trustworthiness (Jason \& Jessica, 2011).

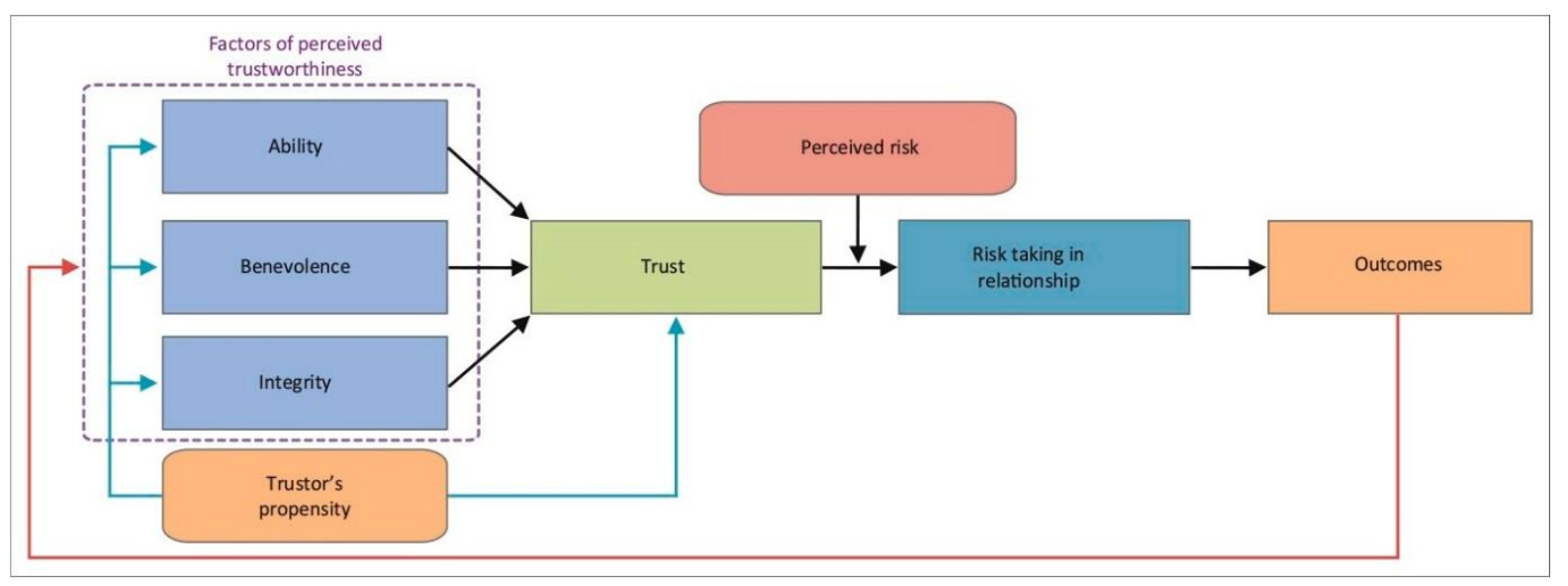

Source: Mayer, R.C., Davis, J.H., \& Schoorman, F.D. (1995). An integrative model of organizational trust. Academy of Management Review, $20,715$.

Figure 3. Organizational trustworthiness model

Based on the above theoretical reasoning and experiential evidence, we therefore propose the following hypothesis:

\subsection{Trustworthiness Has a Positive Relationship with Trust}

\subsubsection{Fairness and Trust}

Fairness and trust were so highly correlated that sometimes respondents discussed them concurrently (Smith and Lindsay 2014), scholar define trust as a the willingness of a party to be vulnerable to the actions of another party based on the expectation that the other will perform a particular action important to the trustor, irrespective of the ability to monitor or control that other party (Mayer et al., 1995) whereby, fairness influences people's trust as 
well as decision making process (Konovsky and Pugh 1994), Fairness heuristic can serve as proxy of trust (Jerald and Jason 2005) supported by trust theory that highlights the relationship as fairness acts as an fundamental of trust (Morgan and Hunt 1994), a recent interdisciplinary literature study of social exchange theory highlighted quotes which indicated the relationship of two person as "the character of the relationship between exchange partners might affect the process of social exchange" meaning that the relationship influences the type of exchange. Yet, that "successful exchanges can cause one individual to become committed to another, which suggesting that an exchange may sometimes affect a relationship" (Cropanzano and Mitchel 2005), which support the finding that the relationship between justice and trust has most often been described using social exchange theory (Jason and Rodell, 2011).

Constantly, we assume that the three fairness frames (distributive, procedural and interactional) will influence customers trust in mobile sector, and with link of our study model which integrate the possibility of a direct relationship between fairness and trust, we therefore propose the following hypotheses:

\section{4- Distributive fairness has a positive relationship with trust.}

5- Procedural fairness has a positive relationship with trust.

\section{6- Interactional fairness has a positive relationship with trust.}

\section{Study's Methodology}

This study conducted descriptive and analytical study design. Specifically, the researchers collected the necessary data and information that will use in the entire study. Primary and secondary data were used for the current study. Primary data were collected through questionnaire. Secondary data (theoretical feedback and previous studies) were collected through different sources of books, scientific journals, and the internet. In more details, in this section the authors outline the selection of the sample, measuring instruments, validity the tool of the study, reliability, statistical methods used, and limitations of the study.

\subsection{Population and Sampling Technique}

The sample used in our study are selected randomly, and consist of 300 customers with different gender, educations, and age, and being briefed about the task and subsequently we have asked the customer to fill in a paper questionnaire which is being carried out by hand, the task took place in different standalone mobile providers retail outlet, and further conducted in different malls and fashion shops in Riyadh City in Saudi Arabia, the sample covers the three mobile companies (STC, Zain, and Mobily) whom are the only main provider for mobile services in the country, further sample information are highlighted in the following tables:

Table 1. Distribution of study sample according to age

\begin{tabular}{lll}
\hline Age & Frequency & $\%$ \\
\hline Less than 20 Years & 10 & 3.3 \\
20 to less than 30 Years & 95 & 31.7 \\
30 to less than 40 Years & 124 & 41.3 \\
40 to less than 50 Years & 41 & 13.7 \\
50 Years or more & 30 & 10.0 \\
Total & 300 & 100 \\
\hline
\end{tabular}

Source: from the results of statistical analysis.

Table 2. Distribution of study sample according to qualification

\begin{tabular}{lll}
\hline Qualification & Frequency & $\%$ \\
\hline High school or less & 67 & 22.3 \\
Bachelor degree & 183 & 61.0 \\
Postgraduate & 20 & 6.7 \\
Other & 30 & 10.0 \\
Total & 300 & 100 \\
\hline
\end{tabular}

Source: from the results of statistical analysis. 
Table 3. Distribution of study sample according to time of dealing with the company

\begin{tabular}{lll}
\hline Time of dealing with the Company & Frequency & $\%$ \\
\hline 1 to less than 3 Years & 80 & 26.7 \\
3 to less than 6 Years & 66 & 22.0 \\
More than 6 Years & 154 & 51.3 \\
Total & 300 & 100 \\
\hline
\end{tabular}

Source: from the results of statistical analysis.

Table 4. Distribution of study sample according to service provider

\begin{tabular}{lll}
\hline The Company Name & Frequency & $\%$ \\
\hline Mobily & 96 & $32 \%$ \\
STC & 170 & $57 \%$ \\
Zain & 34 & $11 \%$ \\
Total & 300 & $100 \%$ \\
\hline
\end{tabular}

Source: from the results of statistical analysis.

\subsection{Study Instrument}

Data was collected by means of a questionnaire designed by the researchers. It consisted of (38) items, which were designed according to (likert scale): strongly disagree, disagree, neither, agree, strongly agree, and given the weights $(1,2,3,4$, and 5). The higher the mean, indicates to higher degree of consent on the item. As the questionnaire was divided into six parts as follows:

Part One: it included a number of items that aim to know the personal data of the sample members (4 items), they are: age, years of dealing with the provider, service provider and educational qualification.

Part Two: it included a number of items that aim to measure the procedural fairness dimensions from the perspective of the sample members (16 items). This items has been divided into a set of items, namely: impartiality: measured by items (1-3), refutability: measured by items (4-6), explanation: measured by items (7-13), familiarity: measured by items (14-16).

Part Three: it included a number of items that aim to measure the distributive fairness dimensions from the perspective of the sample members (8 items: measured by items (17-24).

Part Four: it included a number of items that aim to measure the interactional fairness dimensions from the perspective of the sample members (6 items). This items has been divided into a set of items, namely: bilateral communication: measured by items (25-27), courtesy: measured by items (28-30).

Part Five: it included a number of items that aim to measure trustworthiness dimensions from the perspective of the sample members (4 items: measured by items (31-34).

Part Six: it included a number of items that aim to measure customer trust dimensions from the perspective of the sample members (4 items: measured by items (35-38).

The (38) items were taken from (Roy et al., 2015) study.

\subsection{Validity the Tool of the Study}

To testify the validity of the study, a number of steps were taken: First: a number of questionnaires were distributed to a number of referees, of professors and specialists in managemnt to assess the questions for accuracy. Based on their recommendations and comments, many modifications were done; some items were deleted, new items were added and other items were rephrased until the questionnaire reached its final form. Second: the statistician reviewed the questionnaire in terms of its format, layout, and whether the type of questions were suitable for statistical analysis. Third: a pilot study with thirty participants was conducted to further ensure the validity and reliability of the questionnaire.

\subsection{Reliability}

To examine the harmony of questionnaire statements, the Cronbach's alpha coefficient was used to calculate the internal consistency of the measuring scales the Cronbach's alpha for fairness dimensions. The Cronbach's alpha for these dimensions in table 5. This result indicate that the reliability coefficient for all dimensions is not 
less than (0.60). This also means that the study tool is consistent and valid for the purposes of statistical analysis and scientific study.

Table 5. Cronbach's Alpha for the reliability of the dimensions of survey

\begin{tabular}{lll}
\hline Factors & No. of Items & Alpha \\
\hline Procedural fairness & 16 & 0.92 \\
Distributive fairness & 8 & 0.90 \\
Interactional fairness & 6 & 0.82 \\
Trustworthiness & 4 & 0.89 \\
Customer trust & 4 & 0.92 \\
\hline
\end{tabular}

Source: from the results of statistical analysis.

\subsection{Statistical Methods Used}

The statistical methods were used for statement attributes of the study sample and for examining the hypotheses of the study are: frequencies, percentages, means, standard deviation, correlation coefficients and Pearson correlation.

\subsection{Limitations of the Study}

First, this study is a pioneer investigation in fairness in Saudi Mobile Sector, Saudi Arabia. Thus further study is needed to assess the validity of the findings in a wider context. Second, this study was applied in Riyadh city because (1) the majority of mobile sectors are located in this city (2) constraints of time in data collection and the limitation of financial resources. It is difficult to cover the vast area of Saudi Arabia. Hence the results can only be generalized with caution.

\section{Analysis of the Results}

This section relates the findings obtained through the main instrument of this study, namely the quantitative analysis of the data collected from the questionnaire. This section is structured into one main part touches on the testing of the hypotheses.

\subsection{Examining the Hypotheses of the Study}

Before start with the results of hypotheses and through the use of Statistical Package for Social Sciences (SPSS) will be verified normality distribute for the variables using (Kelmkarov-Smirnov) test.

Table 6. Kelmkarov-Smirnov test

\begin{tabular}{|c|c|c|c|c|c|c|}
\hline Variables & No. & Mean & Std. Deviation & $\begin{array}{l}\text { Kolmogorov-Smirn } \\
\text { ov Z }\end{array}$ & Sig. & Result \\
\hline Procedural Fairness & 300 & 3.22 & 0.64 & 1.100 & 0.178 (N. S.) & Normally \\
\hline Distributive fairness & 300 & 3.06 & 0.84 & 1.068 & 0.204 (N. S.) & Normally \\
\hline Interactional Fairness & 300 & 3.37 & 0.73 & 1.711 & 0.092 (N. S.) & Normally \\
\hline Trustworthiness & 300 & 3.38 & 0.98 & 1.924 & 0.072 (N. S.) & Normally \\
\hline Trust & 300 & 3.26 & 0.95 & 1.192 & 0.122 (N. S.) & Normally \\
\hline
\end{tabular}

Source: from the results of statistical analysis.

As shown in table 6. that the values of (Z) is non-significant, thus fulfilling the researchers distribution of study variables distributed naturally.

\section{Hypothesis 1: distributive fairness has a positive relationship with trustworthiness}

Table 7. Pearson correlation between distributive fairness and trustworthiness

\begin{tabular}{lll}
\hline The correlation coefficient & Sig. (2-tailed) & Describe the relationship \\
\hline 0.7412 & 0.01 & Positive relationship \\
\hline
\end{tabular}

Source: from the results of statistical analysis 
As show in the above table, there is a direct correlation (positive) between distributive fairness and trustworthiness, and this relationship were statistically significant at the level of 0.01 , therefore hypothesis 1 is supported.

\section{Hypothesis 2: Procedural fairness has a positive relationship with trustworthiness}

Table 8. Pearson correlation between procedural fairness and trustworthiness

\begin{tabular}{lll}
\hline The correlation coefficient & Sig. (2-tailed) & Describe the relationship \\
\hline 0.7631 & 0.01 & Positive relationship
\end{tabular}

Source: from the results of statistical analysis.

As show in the above table, there is a direct correlation (positive) between procedural fairness and trustworthiness, and this relationship were statistically significant at the level of 0.01 , therefore hypothesis 2 is supported.

Hypothesis 3: Interactional fairness has a positive relationship with trustworthiness

Table 9. Pearson correlation between interactional fairness and trustworthiness

\begin{tabular}{lll}
\hline The correlation coefficient & Sig. (2-tailed) & Describe the relationship \\
\hline 0.7297 & 0.01 & Positive relationship \\
\hline
\end{tabular}

Source: from the results of statistical analysis.

As show in the above table, there is a direct correlation (positive) between interactional fairness and trustworthiness, and this relationship were statistically significant at the level of 0.01 , therefore hypothesis 3 is supported.

\section{Hypothesis 4: Trustworthiness has a positive relationship with trust:}

Table 10. Pearson correlation between trustworthiness and trust

\begin{tabular}{lll}
\hline The correlation coefficient & Sig. (2-tailed) & Describe the relationship \\
\hline 0.8786 & 0.01 & Positive relationship \\
\hline
\end{tabular}

Source: from the results of statistical analysis.

As show in the above table, there is a direct correlation (positive) between trustworthiness and trust, and this relationship were statistically significant at the level of 0.01 , therefore hypothesis 4 is supported.

\section{Hypothesis 5: Distributive fairness has a positive relationship with trust}

Table 11. Pearson correlation between distributive fairness and trust

\begin{tabular}{lll}
\hline The correlation coefficient & Sig. (2-tailed) & Describe the relationship \\
\hline 0.7275 & 0.01 & Positive relationship \\
\hline
\end{tabular}

Source: from the results of statistical analysis

As show in the above table, there is a direct correlation (positive) between distributive fairness and trust, and this relationship were statistically significant at the level of 0.01 , therefore hypothesis 5 is supported.

Hypothesis 6: Procedural fairness has a positive relationship with trust

Table 12. Pearson correlation between procedural fairness and trust

\begin{tabular}{lll}
\hline The correlation coefficient & Sig. (2-tailed) & Describe the relationship \\
\hline 0.7453 & 0.01 & Positive relationship \\
\hline
\end{tabular}

Source: from the results of statistical analysis. 
As show in the above table, there is a direct correlation (positive) between procedural fairness and trust, and this relationship were statistically significant at the level of 0.01 , therefore hypothesis 6 is supported.

\section{Hypothesis 7: Interactional fairness has a positive relationship with trust}

Table 13. Pearson correlation between interactional fairness and trust

\begin{tabular}{lll}
\hline The correlation coefficient & Sig. (2-tailed) & Describe the relationship \\
\hline 0.7007 & 0.01 & Positive relationship \\
\hline
\end{tabular}

Source: from the results of statistical analysis.

As show in the above table, there is a direct correlation (positive) between interactional fairness and trust, and this relationship were statistically significant at the level of 0.01 , therefore hypothesis 7 is supported.

\section{Discussions}

\section{Hypothesis 1: Distributive fairness has a positive relationship with trustworthiness.}

Our results showed that there is a positive relationship between distributive fairness with trustworthiness which running in parallel to the highlights indicated by anxiety or uncertainty theory as highlighted by the research study of (Jason and Jessica 2011) and elaborated further by (Judith, 2013) that uncomfortably exist in first time relationship between two individual, further our study finding show consistent with (Mourad, 2014) study of organization justice which reported a positive relationship between organization distributive justice and support as employees perform citizenship behaviours, for clarity of the relationship between organization citizen behaviour and trustworthiness, a multi-level cross-cultural study finding that "subordinates organization citizen behaviour significantly positively related to managers affective trust, which in turn positively related to managerial trustworthy behaviour" (Reiche et al., 2013) in a different extension, our study finding show inconsistent with the study of (Seok and Chiew 2013) where it find a non-significant interaction between trustworthiness and justice, whereby we refer this discrepancy due to the sample size and participants background and ages limitation of their study, in due spot concentricity, a study of justice perceptions as predictors of customer satisfaction find out the distributive justice is the most predicator of customer satisfaction (Martínez-Tur et al., 2006) and we thereby recapitulation the importance of distributive justice to build and stand exchange relationship on the borders highlighted by equity theory that individuals focus on how the out came are distributed among customer which in turn end by and led to the trustworthiness relationship.

\section{Hypothesis 2: Procedural fairness has a positive relationship with trustworthiness.}

Our results showed that there is a positive relationship between procedural fairness and trustworthiness, where by our finding is consist with the study of (Oliver, 2008) as the trustworthiness of transformational leadership (trustworthiness, faith and loyalty to the leader) are influenced positively by procedural fairness, moreover the study of (Jason and Jessica 2011) has indicated the same positive relationship between procedural fairness and trust. A meta-analysis conducted in Taiwan of 400 registered nurse (Chen et al., 2015) to measure organization commitment and trust relationship find that organization procedural fairness significantly and positively affected organizational trust and commitment, which support our finding that procedural fairness are crucial segment part that lead to trustworthiness, it worth to highlighted that procedural justice ranked as the second important of customer satisfaction predicators (Martínez-Tur et al., 2006), further study in the mobile related filed find procedural justice has a dominant role in explaining customer service satisfaction recovery as they find procedural justice has the strongest direct effect on satisfaction and exerts both a direct effect on satisfaction and an indirect one a like emotions (Río-Lanza et al., 2009). We therefore refer this positive relationship to the importance of procedural as functional process that are taken into action by the quality of procedural standards in respect of quality fairness of problem solving approach which by the end effecting the trustworthiness basis and that would include all communication tools the firms practise internally or externally such as policy, guidelines, manuals and process.

\section{Hypothesis 3: Interactional fairness has a positive relationship with trustworthiness.}

Our results showed that there is a positive relationship between interactional fairness and trustworthiness, our finding are consist with longitudinal study of (Jason and Jessica 2011) which find reciprocal relationship between interpersonal fairness along with the two factors of trustworthiness "benevolence and integrity" whereby both facet of interactional fairness or sub dimension (interpersonal and informational) reflect positive 
relationship to the trustworthiness. Further elaboration by (Jason and Jessica 2011) suggest that managers who adhered to interpersonal justice rules were perceived to be more trustworthy, and vice versa, moreover they suggest interpersonal justice had a positive effect on perceived benevolence which a facet of trustworthiness as highlighted in the organization model of trustworthiness (Mayer et al., 1995) further our finding are consist with study of (Shueh-Chin, 2013) that interpersonal fairness perceptions (a sub-dimension of interactional fairness) involve positively the manner of interactions between the service provider and consumers, he added also that informational fairness perceptions (a sub-dimension of interactional fairness) involve positively consumers perception about open, thorough, reasonable, and timely information provided by the service provider. The positive relationship reflect the importance of interactional fairness as a key elements of dealing with other and being clear as well as transparent with internal and external customers, as further suggested by the study of (Hocutt et al., 1997) that interactional justice are more important than distributive justice in the scene that interactional justice are first interact with the service recovery than distributive justice.

\section{Hypothesis 4: Trustworthiness has a positive relationship with trust.}

Our results showed that there is a positive relationship between trust and trustworthiness as suggested by organization trust model that trust would lead to trustworthiness (Mayer et al., 1995), our results are consist with finding of (Jason et al., 2007) that trust are correlated with and would lead to trustworthiness, in the same hand our finding goes in parallel with filed comparison and contrast study of (Savolainen and Häkkinen 2011) as they tested trustworthiness of leader behaviour in the context of intra-organizational, inter-personal work relationships, and they highlight that trust influences_organizational processes such as communication, cooperation, and information sharing, and it affects productivity, whereby they conclude that trust would require real effort to achieve trustworthiness and can't be gained by adapting certain leadership or managerial traits only, which the case reflect the importance of trustworthiness relationship to achieve trust and vice verses relationship, "if you hope to appear trustworthy to everyone, it is important that you actually are trustworthy to everyone, this includes your customers, suppliers, employees even your competitors" (Thomas, 2015). Further substantiation of the positive relationship importance of being trustworthy company, a study of benefits and drive of trust conducted by (Concerto Marketing Group and Research now Survey, 2009) of 1000 participant in north America, find out that when people trust a brand, $83 \%$ will recommend it to other people, $82 \%$ will use its product and service frequently, $78 \%$ will look to it first for the things they want, $78 \%$ will give its new products and services a chance, $50 \%$ will pay more for its products and services, $47 \%$ believes it will inform them about products and services they will like, hence the study recommend company to build trust relationship in order to be trustworthy to its customers.

\section{Hypothesis 5: Distributive fairness will have a positive relationship with trust.}

Our results showed that there is a positive relationship between distributive fairness and trust which consist with the study of (Liu et al., 2012) conducted in the context of buyer-supplier relationship, where they find perceptions of distributive justice are positively related to buyer-supplier coupling behaviours, whereby coupling behaviours refer to commitment and relationship which reflects and build the trust relationship, distributive justice is crucial aspect to customer understanding of fairness as it related to customer assessment of product or services outputs verses his/her input which reflects into the trust relationship, the illustration raised further in the study of price fairness perception recommendation to pricing manager to decrease transaction similarity as customers perceive two transactions as similar thus the effect of observed price differences on perceptions of price unfairness is greater than other situation. (Lan Xia et al., 2004)

\section{Hypothesis 6: Procedural fairness will have a positive relationship with trust.}

Our results showed that there is a positive relationship between procedural fairness and trust, which consist with earlier literature study in the field of logistic outsourcing relationship where they find a positive relationship between procedural fairness and trust (Hofer et al., 2012) further our research finding consist with (Bidarian and Jafari 2012) as it find a strong relationship between procedural justice and organizational trust. The importance of procedural fairness reflected in the study of (Chapuis, 2012) which find consumers perceptions of fairness appear during the buying process, not only at the time of consumption, we based on those various finding, refer the importance of procedural fairness to the proper and pre-tested procedural and process which would reflect positively on customer trust relationship.

\section{Hypothesis 7: Interactional fairness will have a positive relationship with trust.}

Our results showed that there is a positive relationship between interactional fairness and trust, whereby it consist with study of customer trust in the services recovery in Brazil (Santos and Fernandes 2008) which find interactional fairness impact customer trust positively, that would indicate the importance of having proper and 
respectful interactional relationship reflected by the way customer are being treated and dealt with, and from other side would highlight the need from mobile companies to be transparent and clear of the information they exchange with the customer, as interactional relationship proven to impact the trust relationship directly as highlighted by (Preis, 2003) that the gratification buyers receive from relationships with sales people, is an important component of overall customer satisfaction, whereby gratification are indicated as interpersonal satisfaction.

\section{Recommendations}

Our findings presented significant and positive relation to all tested hypotheses which prove that different dimensions of fairness has empirical role and relationship with trust and trustworthiness. Therefore it is very important for mobile companies to adapt best practices of distributive, procedural and interactional fairness to gain customer loyalty and trust, a direct highlight to mobile companies that being equal of allocation of rewards and costs, and being rational on decision, and transparent or logical of the process doesn't necessary means the firm has achieved fairness entirety, as the customer doesn't look only at that, but far away, to the extent of comparison standard and contributed percentile/ratio of the prices, product and services or even after sales to the profit and community social responsibility (CSR) sharing. Further it has been proven that there is a need for training need analysis (TNA) to measure the gap of between what skills, knowledge and attitude (KSA) the staff presently adapting verses the needed toward the different fairness dimension, for example the staff should be skilled to understand and identify present internal and external process (procedural fairness), they should be able to measure the outcome of responses as well as expectation of customers (distributive fairness) and understanding customers different need and respond to it efficiently and properly (interactional fairness), moreover there are a need to measure business performance (MBP) in respect of different company systems that interact direct and in-direct with customers relationship for example customer satisfaction feedback (distributive fairness), online sales (procedural fairness), tool free respond timing (Interactional fairness). As for the unique relationship between trust and trustworthiness, we would highlight that such relationship can't be attained through show-off or line-up certain process or adapting the practices of being fair, instead it is something that goes further to built-in cognitive tacit knowledge, in commercial context of mobile companies, to be trustworthy firm, the process should start from the vision and mission the firms adapting, along ward the strategy and even daily micro transactions done internal and external of the business.

Finally, competition are no more limited locally due international and global company start entering the market directly through third party agreement, for example some company adapt the practices of assigning their tool free not to local supplier, instead they assign it to a pan-gulf agents which it based on other countries a like chain or India and recently Jordan, and that may refer to the cost control and efficiency in handling the customer request which present procedural and interactional fairness, in extended example of retail company, Amazon, eBay or Aliexpress start celling mobile devices internationally before the local mobile companies do so which would refer to distributive fairness, which indicate that the competition borders are extended to three dimension: (A) Local competition, (B) International competition, (C) other sectors competition, and we would refer that competition expansion to competitive five forces (Porter, 1989) which are guided by customer demand of fairness different aspects from the service provider, whereby we would refer fairness as influencer of five forces or as the six force of competiveness as the importance of fairness would determine wither a firm can be in or out of the competition.

\section{Future Research Recommendations}

One of the borders present a challenge for us and would do so for potential scholars and researchers unless it cleared, is to have a clear stand of the different dimensions of fairness and the different facets of trustworthiness. Further as per the general authority of statistics of Saudi Arabia 2016 report, the total population is 31,742,580 where $63.2 \%$ are Saudi citizen and $36.8 \%$ are foreigners who are also considered as a customer for mobile sector whereby many of them doesn't speak Arabic which in turn would affect the quality of the result as the Arabic questionnaire would not necessary cover major part of the customers, thus we recommend to develop a bilingual questionnaire for better result, in the same extent Saudi Arabia consists of 13 administrative area, across 5 provinces, thus we recommend a wider coverage area either by provinces or by administrative areas which would result in better coverage of customers.

\section{Acknowledgements}

The researchers thank the deanship of scientific research at King Saud University represented by the College of Business Administration Research Center for the financial support of this study. 


\section{References}

Adams, J. S. (1965). Inequity in Social Exchange. In L. Berkowitz (Ed.), Advances in Experimental Social Psychology (vol. 2, pp. 267-299). New York: Academic Press. https://doi.org/10.1016/s0065-2601(08)60108-2

Aljazira Capital. (2016). Saudi Telecom Sector. Retrieved December 7, 2016, from http://www.aljaziraapital.com.sa/report_file/ess/SEC-288.pdf

Árnadóttir, S. P. (2002). Fairness Heuristic Theory: Valid But Not Empirical. Scandinavian Journal of Psychology, 43(4), 353-362. https://doi.org/10.1111/1467-9450.00303

Bidarian, S., \& Jafari, P. (2012). The Relationship between Organizational Justice and Organizational Trust. Procedia - Social and Behavioural Sciences, 47, 1622-1626. https://doi.org/10.1016/j.sbspro.2012.06.873

Blau, P. M. (1964). Justice in Social Exchange. Sociological Inquiry, 34(2), $193-206$. https://doi.org/10.1111/j.1475-682x.1964.tb00583.x

Chapuis, J. (2012). Price Fairness Versus Pricing Fairness. SSRN Electronic Journal. https://doi.org/10.2139/ssrn.2015112

Chen, Su-Yueh, Wen-Chuan Wu, Ching-Sheng Chang, Chia-Tzu Lin, Jung-Yuan Kung, Hui-Ching Weng, Yu-Tz Lin, \& Shu-I Lee. (2015). Organizational Justice, Trust, and Identification and Their Effects on Organizational Commitment in Hospital Nursing Staff. BMC Health Services Research, 15(1), 1-363 https://doi.org/10.1186/s12913-015-1016-8

Cohen-Charash, Y., \& Spector, P. E. (2001). The Role of Justice in Organizations: A Meta-Analysis. Organizational Behaviour and Human Decision Processes, 86(2), $278-321$. https://doi.org/10.1006/obhd.2001.2958

Collie, T., Bradley, G., \& Sparks, B. A. (2002). Fair Process Revisited: Differential Effects of Interactional and Procedural Justice in the Presence of Social Comparison Information. Journal of Experimental Social Psychology, 38(6), 545-555. https://doi.org/10.1016/s0022-1031(02)00501-2

Colquitt, J. A. (2001). On the Dimensionality of Organizational Justice: A Construct Validation of a Measure. Journal of Applied Psychology, 3(86), 386-400. https://doi.org/10.1037//0021-9010.86.3.386

Concerto Marketing Group and Research now Survey. (2009). Brand Trust: The Six Drivers of Trust. Retrieved November 28, 2016, from http://www.slideshare.net/nickblack/brand-trust-the-six-drivers-of-trust-2193957

Cropanzano, R., \& Mitchel, S. M. (2005). Social Exchange Theory: An Interdisciplinary Review. Journal of Management, 31(6), 874-900. https://doi.org/10.1177/0149206305279602

Dobbie, F., Arthur, F. S., \& Jones N. (2010). Building Understanding of Fairness, Equality and Good Relations in Scotland. Equality and Human Rights Commission Research Report, 53, 1-122. https://www.equalityhumanrights.com/sites/default/files/research-report-54-building-understanding-of-fairn ess-equality-and-good-relations-in-scotland.pdf

Forsyth, D. R. (2006). Group Dynamics (5th ed.). Belmont, CA: Wadsworth, Cengage Learning.

General Authority of Statistics. (2016). Population by Age Groups, Gender and Nationality (Saudi/Non- Saudi). Retrieved December 19, 2016, from http://www.stats.gov.sa/sites/default/files/estm_pop_2016_3.pdf

Glacier By Sanlam. (2013). To Be Fair Understanding the Fundamentals of the New Financial Services Regulations. http://glacier-events.co.za/tcf/downloads/TCF_handbook.pdf

Harris, J. D., Moriarty, B., \& Wicks, A. C. (2014). Public Trust in Business. Cambridge, United Kingdom: Cambridge University Press.

Hayek, F. A. (1978). Law, Legislation and Liberty: The Mirage of Social Justice. University of Chicago Press.

Hocutt, M. A., Goutam, C., \& John, C. M. (1997). The Impact of Perceived Justice on Customer Satisfaction and Intention to Complain in a Service Recovery. Association for Consumer Research, 24, 457-463. http://acrwebsite.org/volumes/8086/volumes/v24/NA-24

Hofer, A. R., Knemeyer, A. M., \& Murphy, P. R. (2012). The Roles of Procedural and Distributive Justice in Logistics Outsourcing Relationships. Journal of Business Logistics, 33(3), 196-209. https://doi.org/10.1111/j.2158-1592.2012.01052.x

Hough, M., Jackson, J., Bradford, B., Myhill, A., \& Quinton, P. (2010). Procedural Justice, Trust, and 
Institutional Legitimacy. Policing, 4(3), 203-210. doi:10.1093/police/paq027

Huseman, R. C., Hatfield, J. D., \& Miles, E. W. (1987). A New Perspective on Equity Theory: The Equity Sensitivity Construct. The Academy of Management Review, 12(2): 222-234. https://doi.org/10.5465/AMR.1987.4307799

Jason A. C., Scott, B. A., \& Lepine, J. A. (2007). Trust, Trustworthiness, and Trust Propensity: a Meta-Analytic Test of Their Unique Relationships with Risk Taking and Job Performance. Journal of Applied Psychology, 92(4), 909-927. https://doi.org/10.1037/0021-9010.92.4.909

Jason, A. C., \& Jessica, B. R. (2011). Justice, Trust, and Trustworthiness: A Longitudinal Analysis Integrating Three Theoretical Perspectives. Academy of Management Journal, 54(6), 1183-1206. https://doi.org/10.5465/amj.2007.0572

Jenkins, O. B. (2000). The Meaning of Fairness. Orvillejenkins.com. Retrieved 28 November 2016, from http://orvillejenkins.com/faithlife/fairnessfl.html.

Jerald, G., \& Jason, A. C. (2005). Handbook of Organizational Justice. Mahwah, NJ: Lawrence Erlbaum Associates.

Judith, D. (2013). Communication for Business and the Professions: Strategies and Skills. Frenchs Forest, N.S.W.: Pearson Australia.

Konovsky, M. A., \& Pugh, S. D. (1994). Citizenship Behaviour and Social Exchange. Academy of Management Journal, 37(3), 656-669. https://doi.org/10.2307/256704

Kunard, L., \& Moe, C. (2015). Procedural Justice for Law Enforcement: an Overview. Washington: Center for Public Safety and Justice, University of Illinois. https://ric-zai-inc.com/Publications/cops-p333-pub.pdf

Lan, X., Kent, B. M., \& Jennifer, L. C. (2004). The Price is Unfair! A Conceptual Framework of Price Fairness Perceptions. Journal of Marketing, 68(4), 1-15. https://doi.org/10.1509/jmkg.68.4.1.42733

Lind, E., Kray, L., \& Thompson, L. (2001). Primacy Effects in Justice Judgments: Testing Predictions from Fairness Heuristic Theory. Organizational Behaviour and Human Decision Processes, 85(2), 189-210. https://doi.org/10.1006/obhd.2000.2937

Liu, Y., Huang, Y., Luo, Y., \& Zhao, Y. (2012). How Does Justice Matter in Achieving Buyer-Supplier Relationship Performance? Journal of Operations Management, 30(5), 355-367. https://doi.org/10.1016/j.jom.2012.03.003

Loch, C. H., Sting, F. J., Huchzermeier, A., \& Decker, C. (2012). Finding the Profit in Fairness. Harvard Business Review, 90(10), 111-115. http://hdl.handle.net/1765/38069

Martínez-Tur, V., Peiró, J. M., Ramos, J., \& Moliner, C. (2006). Justice Perceptions as Predictors of Customer Satisfaction: the Impact of Distributive, Procedural, and Interactional Justice. Journal of Applied Social Psychology, 36(1), 100-119. https://doi.org/10.1111/j.0021-9029.2006.00005.x

Matt, Z. (2011). The Libertarian Critique of Distributive Justice. Bleeding Heart Libertarians. Bleeding Heart $\begin{array}{lllll}\text { Libertarians. } & \text { Retrieved } & 28 & \text { November } & 2016,\end{array}$ http://bleedingheartlibertarians.com/2011/09/the-libertarian-critique-of-distributive-justice/

Mattila, A. S. (2001). The Effectiveness of Service Recovery in a Multi - Industry Setting. Journal of Services Marketing, 15(7), 583-596. https://doi.org/10.1108/08876040110407509

Mayer, D. M. (2009). Distributive Justice. Encyclopedia of Social Psychology. https://doi.org/10.4135/9781412956253.n157

Mayer, R. C., Davis, J. H., \& Schoorman, F. D. (1995). An Integrative Model of Organizational Trust. Academy of Management Review, 20(3), 709-734. https://doi.org/10.5465/amr.1995.9508080335

Michelle, M. (2013). Distributive Justice. Beyond Intractability. Beyondintractability.org. Retrieved 28 November 2016, from http://www.beyondintractability.org/essay/distributive-justice

Miner, J. B. (2003). The Rated Importance, Scientific Validity, and Practical Usefulness of Organizational Behaviour Theories: A Quantitative Review. Academy of Management Learning and Education, 2(3), 250-268. https://doi.org/10.5465/AMLE.2003.10932132

Ministry of Commerce and Investment. (2014). The Kingdom Regions. Retrieved December 19, 2016, from http://mci.gov.sa/en/AboutKingdom/Pages/KingdomRegions.aspx 
Ministry of Communication and Information Technology. (2016). Brief History. Mcit.gov.sa. Retrieved 28 November 2016, from http://www.mcit.gov.sa/En/aboutmcit/pages/briefhistory.aspx

Mitsubishi Cooperation. (2006). Mitsubishi Corporation Sustainability Report. CSR Policies and Management. http://www.mitsubishicorp.com/jp/en/csr/library/pdf/06sr-10.pdf

Morgan, R. M., \& Hunt, S. D. (1994). The Commitment-Trust Theory of Relationship Marketing. Journal of Marketing, 58(3), 20-38. https://doi.org/10.2307/1252308

Mourad, M. (2014). Organization Justice, Support and Trust: Evidence from Saudi Companies. Journal of Economics, Business and Management, 1(2), 22-25. https://doi.org/10.7763/joebm.2014.v2.92

Nguyen, Q., Villeval, M., \& Xu, H. (2012). Trust and Trustworthiness Under the Prospect Theory: A Field Experiment in Vietnam. SSRN Electronic Journal, 6851, 1-59. https://doi.org/10.2139/ssrn.2144628

Oliver, E. N. (2008). Procedural Justice and Trust: the Link in the Transformational Leadership - Organizational Outcomes Relationship, University of Malaysia Sarawak International. Journal of Leadership Studies, 4(1), $82-100$

Porter, M. E. (1989). How Competitive Forces Shape Strategy. Readings in Strategic Management, 133-143. https://doi.org/10.1007/978-1-349-20317-8_10

Prathamesh, M. (2012). Influence of Interactional Justice on the Turnover Behavioural Decision in an Organization. Journal of Behavioural Studies in Business, 5, 31-41. https://ssrn.com/abstract=2180697

Preis, M. W. (2003). The Impact of Interpersonal Satisfaction on Repurchase Decisions. The Journal of Supply Chain Management, 39(3), 30-38. doi:10.1111/j.1745-493x.2003.tb00157.x.

Reiche, B. S., Cardona, P., Lee, Y. T., Canela, M. Á., Akinnukawe, E., Briscoe, J. P., Bullara, C., Caparas, M. V., Caprar, D. V., Charlemagne, D., Grenness, T., He, W., Jamro, K., Kainzbauer, A., Koester, K., Lazo, A., Moreno, A., Morley, M. J., Myloni, V., Nadeem, S., Aguirre Nieto, M., Svishchev, A., Taylor, S. N., \& Wilkinson, H. (2013). Why do Managers Engage in Trustworthy Behaviour? A Multilevel Cross-Cultural Study in 18 Countries. Personnel Psychology, 67(1), 61-98. https://doi.org/10.1111/peps.12038

Río-Lanza, A. B., Vázquez-Casielles, R., \& Díaz-Martín, A. M. (2009). Satisfaction with Service Recovery: Perceived Justice and Emotional Responses. Journal of Business Research, 62(8), 775-781. https://doi.org/10.1016/j.jbusres.2008.09.015

Robert, L. (2016). This Year's Best Employers Have Focused on Fairness Fortune. Retrieved 28 November 2016, from http://fortune.com/2016/03/03/best-companies-2016-intro/

Robert, N. (1974). Anarchy, State and Utopia. New York: Basic Books.

Roy, S., Devlin, J., \& Sekhon, H. (2015). The Impact of Fairness on Worthiness and Trust in Banking. Journal of Marketing Management, 31(9), 996-1017.

Santos, C. P., \& Fernandes, D. V. (2008). Antecedents and Consequences of Consumer Trust in the Context of Service Recovery. Brazilian Administration Review, 5(3), 225-244. https://doi.org/10.1590/s1807-76922008000300005.

Savolainen, T., \& Häkkinen, S. (2011). Trusted to Lead: Trustworthiness and its Impact on Leadership. Retrieved December 07, 2016, from http://timreview.ca/article/429

Schermerhorn, J. R., Osborn, R., \& Hunt, J. G. (2003). Organizational Behaviour (8th ed.). New York: Wiley.

Seok, B. S., \& Chiew, T. C. (2013). Trust, Trustworthiness and Justice Perception toward the Head of Department. Global Journal of Arts Humanities and Social Sciences, 1(1): 20-29.

Shueh-Chin, T. (2013). Service Fairness Scale: Development, Validation, and Structure. IJMS International Journal of Marketing Studies, 5(6), 25-36. https://doi.org/10.5539/ijms.v5n6p25

Smith, J. G., \& Lindsay, J. B. (2014). Beyond Inclusion: Work-Life Interconnectedness, Energy, and Resilience. New York, NY: Palgrave Macmillan.

Sutton, R., \& Douglas, K. (2013). Social Psychology. New York: Palgrave Macmillan.

Thomas, M. (2015). Is Trust Important in Business? - Entre-Propel.com. Retrieved November 28, 2016, from http://www.entre-propel.com/long-term-growth/is-trust-important-in-business

Wan, H. L. (2015). Introduction to Organisational Justice and Organisational Citizenship Behaviour. Governance and Citizenship in Asia Organisational Justice and Citizenship Behaviour in Malaysia, 1-20. 
https://doi.org/10.1007/978-981-10-0030-0_1

Zapata-Phelan, C. P., Colquitt, J. A., Scott, B. A., \& Livingston, B. (2009). Procedural Justice, Interactional Justice, and Task Performance: The Mediating Role of Intrinsic Motivation. Organizational Behaviour and Human Decision Processes, 108(1), 93-105. https://doi.org/10.1016/j.obhdp.2008.08.001

\section{Copyrights}

Copyright for this article is retained by the author(s), with first publication rights granted to the journal.

This is an open-access article distributed under the terms and conditions of the Creative Commons Attribution license (http://creativecommons.org/licenses/by/4.0/). 